\title{
BMJ Open What do we know about demand, use and outcomes in primary care out-of- hours services? A systematic scoping review of international literature
}

\author{
Hamish Foster, Keith R Moffat, Nicola Burns, Maria Gannon, Sara Macdonald,
} Catherine A O'Donnell

To cite: Foster H, Moffat KR, Burns $\mathrm{N}$, et al. What do we know about demand, use and outcomes in primary care outof-hours services? A systematic scoping review of international literature. BMJ Open 2020;10:e033481. doi:10.1136/ bmjopen-2019-033481

- Prepublication history and additional material for this paper are available online. To view these files, please visit the journal online (http://dx.doi. org/10.1136/bmjopen-2019033481).

Received 06 August 2019 Revised 03 December 2019 Accepted 05 December 2019

Check for updates

(c) Author(s) (or their employer(s)) 2020. Re-use permitted under CC BY-NC. No commercial re-use. See rights and permissions. Published by BMJ.

General Practice and Primary Care, University of Glasgow, Glasgow, UK

Correspondence to

Professor Catherine A O'Donnell; Kate.0'Donnell@glasgow.ac.uk

\section{ABSTRACT}

Objective To synthesise international evidence for demand, use and outcomes of primary care out-of-hours health services (0OHS).

Design Systematic scoping review.

Data sources CINAHL; Medline; PsyARTICLES; PsycINFO; SocINDEX; and Embase from 1995 to 2019.

Study selection English language studies in UK or similar international settings, focused on services in or directly impacting primary care.

Results 105 studies included: $54 \%$ from mainland Europe/Republic of Ireland; 37\% from UK. Most focused on general practitioner-led out-of-hours cooperatives. Evidence for increasing patient demand over time was weak due to data heterogeneity, infrequent reporting of population denominators and little adjustment for population sociodemographics. There was consistent evidence of higher $00 \mathrm{HS}$ use in the evening compared with overnight, at weekends and by certain groups (children aged $<5$, adults aged $>65$, women, those from socioeconomically deprived areas, with chronic diseases or mental health problems). Contact with 00HS was driven by problems perceived as urgent by patients. Respiratory, musculoskeletal, skin and abdominal symptoms were the most common reasons for contact in adults; fever and gastrointestinal symptoms were the most common in the under-5s. Frequent users of daytime services were also frequent $\mathrm{OOHS}$ users; difficulty accessing daytime services was also associated with OOHS use. There is some evidence to suggest that $00 \mathrm{HS}$ colocated in emergency departments (ED) can reduce demand in EDs.

Conclusions Policy changes have impacted on 0OHS over the past two decades. While there are generalisable lessons, a lack of comparable data makes it difficult to judge how demand has changed over time. Agreement on collection of $\mathrm{OOHS}$ data would allow robust comparisons within and across countries and across new models of care. Future developments in $00 \mathrm{HS}$ should also pay more attention to the relationship with daytime primary care and other services.

PROSPERO registration number CRD42015029741.

\section{INTRODUCTION}

Out-of-hours $(\mathrm{OOH})$ primary care is a key element of many healthcare systems. It is
Strengths and limitations of this study

- Systematic scoping review of six medical, psychological and sociological databases and including a diverse range of study designs.

- Searches covering a time frame of recognised international change in the provision of out-of-hours health services (OOHS) from 1995 to 2019.

- A focus on English language papers and on health systems broadly similar to UK primary care may have led to some relevant papers from other health systems being missed.

- The inclusion of 105 papers reporting on demand, use and outcomes of $00 \mathrm{HS}$ is the largest review to date of $00 \mathrm{HS}$ use and provision.

defined as care delivered outside 'normal working hours', when daytime family or general practice is closed; typically between 17:00 or $18: 00$ and 08:00 on weekdays, all weekend and public holidays. ${ }^{1}{ }^{2}$ However, the provision of $\mathrm{OOH}$ care continues to face challenges, in particular rising demand and difficulties in recruiting general practitioners (GP) / family doctors to work in out-of-hours health services (OOHS). ${ }^{2}$

These difficulties have led to numerous attempts at both reorganising $\mathrm{OOH}$ healthcare and implementing new models of care. Policy change in many European countries supported a switch from personal or small rota-based systems of family doctors/GPs providing care for their own patients on a practice list or using a commercial deputising services, to regional cooperatives of GPs providing OOHS for all patients within a geographical region..$^{2-4}$ In the UK, a shift in funding arrangements for OOHS in 1995 encouraged GPs to work collaboratively in $\mathrm{OOH}$ cooperatives. ${ }^{5}$ In 2004, contractual changes to the General Medical Services contract then gave GPs the option 
of transferring responsibility for OOHS to local health authorities. This change, however, presented major challenges for health authorities, with an increasing lack of GPs to run services. As a result, there has been ongoing development of new models of OOHS such as out-ofhours primary care centres (OOHC), walk-in centres (WIC), minor injury units and national or centralised telephone triage and advice (TTA) services. ${ }^{6}$ Based on the primary care setting, these models of care are staffed by a range of professionals, including nurse practitioners, call handlers and emergency care practitioners as well as GPs. ${ }^{67}$ Similar reorganisations have been documented in other high-income countries. ${ }^{28}$ In the Netherlands, for example, around half of the primary care cooperatives have now integrated with hospital emergency departments (ED) to offer a single access point to emergency and $\mathrm{OOH}$ primary care, with the suggestion that attendances at EDs decreased by about $13 \%$.

However, to date, little is known about the impact of these different models on demand for, and use of, OOHS across different healthcare systems. Nor is it clear how demand might have changed over this period of service reorganisation. Such information may help policymakers design and provide services that meet population need and demand. As part of a wider scoping review of OOHS commissioned by the Scottish Government to inform their strategy for OOHS nationally, ${ }^{9}$ we report here on the international evidence of demand, use and outcomes of care associated with OOHS.

\section{METHODS}

The work reported here was part of a wider systematic scoping review designed to identify the international literature relating to the provision of $\mathrm{OOH}$ primary medical care. Scoping reviews are particularly suited to research designed to inform policy, where the research aims are broad in scope and the studies included encompass a range of research approaches and designs. ${ }^{10-12}$ However, scoping reviews are undertaken with the same degree of rigour as more traditional systematic reviews, paying attention to Preferred Reporting Items for Systematic Reviews and Meta-Analyses criteria. ${ }^{12} 13$ The study review protocol is available at www.crd.york.ac.uk/PROSPERO.

\section{Search strategy}

Six databases were searched using Ovid and EBSCOHost: CINAHL; Medline; PsyARTIClES; PsycINFO; SocINDEX; and Embase using terms related to primary care $\mathrm{OOH}$ services. The full search strategy is included in online supplementary appendix 1 . Manual searches of key journals were also conducted and identified two additional papers. The initial search time frame was from 1995, when key changes took place in the organisation of UK OOH services, to December 2017. An update was conducted in March 2019.

\section{Study selection and quality assessment}

All searches were saved into Endnote and duplicates removed. Articles were then screened in the review

\section{Box 1 Inclusion and exclusion criteria}

Studies were included if they met both of the following criteria:

- Based in UK or similar international primary care setting with recognised out-of-hours health services $(00 \mathrm{HS})$, that is, Europe, Australasia, USA or Canada.

- Studies of $00 \mathrm{HS}$ or services which impact directly on primary care, including:

- Out-of-hours telephone-based services such as NHS 24, NHS Direct and NHS 111 service.

- Emergency department (ED) initiatives designed to interface with primary care services.

- Community-based or social work services designed to interface with primary care services.

Studies were excluded if they met any of the following criteria:

- Focus on dentistry, social work services, ED or other services not operating within or interfacing with primary care.

- Editorials, opinion pieces or commentaries.

- Evaluation reports of new services.

- Policy documents produced by government agencies or position statements from professional bodies.

Not written in English language.

management software DistillerSR, using predefined inclusion and exclusion criteria (box 1). All study designs were included. Two authors (drawn from CAOD, HF, KM, NB, $\mathrm{MG}$ and $\mathrm{SMcD}$ ) independently assessed the abstracts and full papers for eligibility; disagreements were resolved by discussion, with reference to a third team member if required.

Study characteristics were extracted for all included papers by HF, KM, NB, MG and CAOD (two reviewers per paper). Papers were quality assessed using recognised checklists based on the Critical Appraisal Skills Programme (CASP) checklists (https://casp-uk.net/casp-tools-checklists/) for observational studies, randomised controlled trials and reviews/systematic reviews. Each paper was appraised by two members of the team, led by CAOD and HF, supported by KM, NB, MG and SMcD. Papers were judged good if no element of the design was judged to be poor; fair if they were assigned one poor score; and poor if they were assigned two or more poor scores. CAOD reviewed the papers identified in the update search.

\section{Data extraction and analysis}

Thematic analysis focused on the aims of the study; the population group; key findings and how this fitted to the key areas of interest to the Scottish Out-of-Hours Review Group. Discussion with the Review Group identified four major areas of interest, namely: patient demand; new models of care; use of information technology; and quality and safety of care. In this paper, we focus on those papers addressing patient demand, as well as outcomes associated with that demand. The summary table is presented in online supplementary appendix 2. Some papers gave an estimated or adjusted rate of contact per annum. If these data were not provided crude contact rates were calculated, if possible. This relied on the paper giving information on (1) the size of population covered; (2) 
the number of patient contacts; and (3) a time frame for data collection. These were calculated by HF, in discussion with CAOD.

\section{Patient and public involvement}

Our research question was generated as part of the wider Scottish Government's National Review of Primary Care Out-of-Hours Services. For that wider review, as part of a National Engagement Programme, there were extensive engagement and consultation exercises. The exercises included health board visits and public discussion groups with $\mathrm{OOH}$ services staff and patient representatives. Patients or the public were not directly involved in the design or conduct of this scoping review. The early results of the scoping review were made publicly available at https://www.gov.scot/publications/ main-report-national-review-primary-care-out-hoursservices/.

\section{RESULTS}

\section{Study characteristics}

The search identified 2548 papers, with 400 finally included (figure 1). A description of all the identified papers is available on request to CAOD. Here, we report on the 105 papers which reported on the theme of demand, use and outcomes (see online supplementary appendix 2 for a summary of these papers). Over half were studies conducted in mainland Europe or Ireland, with the Netherlands $(n=18)$ and Norway $(n=11)$ predominant; onethird were set in the UK, mainly England; six were based
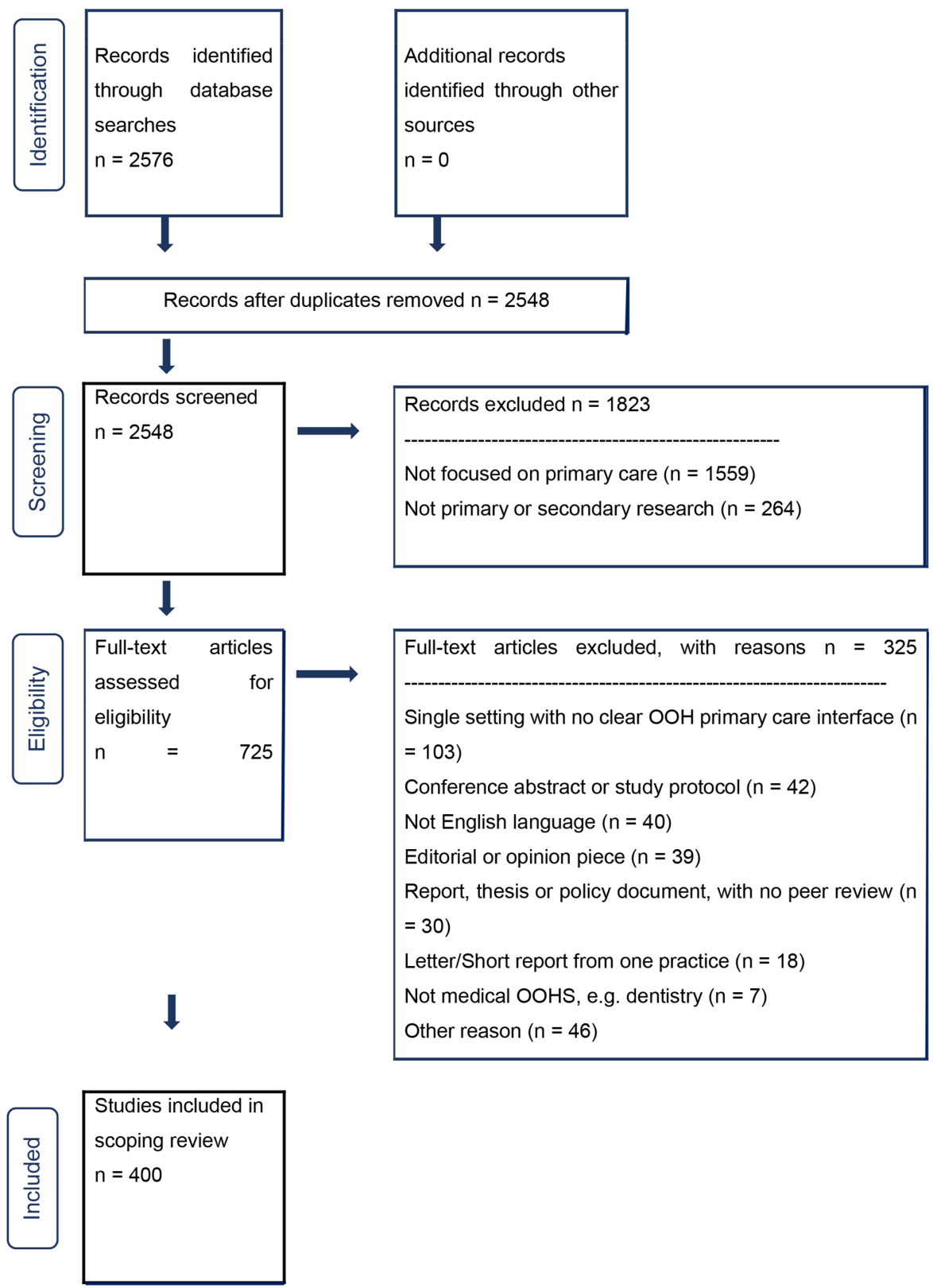

Figure 1 Preferred Reporting Items for Systematic Reviews and Meta-Analyses (PRISMA) flow diagram. OOH, out of hours; OOHS, out-of-hours health services. 
Table 1 Characteristics of the included papers addressing demand, use and outcomes in OOHS

\begin{tabular}{lc}
\hline Characteristics & $\begin{array}{c}\text { Number (\%) } \\
\text { of papers }\end{array}$ \\
\hline Country/regional setting ( $\mathrm{n}=105)$ & \\
\hline Mainland Europe and Republic of Ireland & $57(54.3)$ \\
\hline UK & $37(35.2)$ \\
USA, Australia, or New Zealand & $6(5.7)$ \\
\hline International & $5(4.8)$ \\
Year of publication ( $n=105)$ & \\
\hline 1995-1999 & $14(13.3)$ \\
\hline $2000-2004$ & $14(13.3)$ \\
\hline $2005-2009$ & $16(15.2)$ \\
\hline $2010-2014$ & $29(27.7)$ \\
\hline 2015-2019 (up to March 2019) & $32(30.5)$ \\
\hline Study design ( $n=105)$ & \\
\hline Routine data analysis & $41(39.1)$ \\
\hline Retrospective case review & $17(16.2)$ \\
\hline Prospective case review & $14(13.3)$ \\
\hline Observational (case-control or cohort studies) & $6(5.7)$ \\
\hline Questionnaire/survey & $14(13.3)$ \\
\hline Mixed methods & $5(4.8)$ \\
\hline Reviews/systematic reviews & $5(4.8)$ \\
\hline Other & $3(2.8)$ \\
\hline
\end{tabular}

Patient focus $(n=101)$

$\begin{array}{lc}\text { General } & 63(63.4) \\ \text { Adults (aged } 16 \text { and over) } & 2(2.0) \\ \text { Elderly only (65 years and over) } & 2(2.0) \\ \text { Children (under } 16 \text { years) } & 6(5.9) \\ \text { Cancer/palliative patients } & 6(5.9) \\ \text { Mental health/psychiatric patients } & 4(4.0)\end{array}$

Other (includes frequent attenders (4); patients with 18 (17.8) chronic disease (4); migrant patients $(n=2)$ )

Main setting $\left(n=151^{\star}\right)$

\begin{tabular}{lc} 
GP out-of-hours cooperative & $86(57.0)$ \\
Accident and emergency/emergency department & $21(13.9)$ \\
$\begin{array}{l}\text { Telephone triage service (eg, NHS Direct, NHS 24, } \\
\text { NHS 111) }\end{array}$ & $12(8.0)$ \\
GP deputising service & $9(5.9)$ \\
Urgent care centre & $4(2.6)$ \\
Walk-in clinic & $3(2.0)$ \\
$\begin{array}{l}\text { Other (eg, ambulance; casualty clinic; community } \\
\text { hospital; minor injury unit; OOH palliative care }\end{array}$ & $16(10.6)$ \\
service; daytime general practice) & \\
\hline
\end{tabular}

*More than 105 due to multiple settings in some papers. GP, general practitioner; NHS, National Health Service; $\mathrm{OOH}$, out of hours; OOHS, out-of-hours health services.

in the USA, Australia or New Zealand; and five were set in multiple countries (table 1). The majority of papers focused on the general population of users rather than on particular groups. Observational study designs predominated, in particular the use of routinely collected data from OOHS $(\mathrm{n}=41,39.1 \%)$; prospective or retrospective record reviews $(\mathrm{n}=31,29.5 \%)$ and questionnaire surveys $(\mathrm{n}=14,13.3 \%)$. Most reported studies were cross-sectional in design. Study quality was generally fair or good. A majority of studies reported on GP-led $\mathrm{OOH}$ cooperative models $(\mathrm{n}=86)$, but there were also studies examining use in EDs $(n=21)$; telephone triage services $(n=12)$; GP deputising services $(n=9)$; and urgent care or WICs $(\mathrm{n}=7)$.

Six main subthemes were identified: patterns of use; time of use and demographics of users; urgency and presenting symptoms; proximity to OOHS and relationship with daytime services; OOHS outcomes; and the wider impact of new models of OOHS. These are discussed in turn below.

\section{Patterns of use}

Prior to services recording patient contacts themselves, either manually or electronically, studies used proxies for $\mathrm{OOH}$ work (eg, night visit claim fees) which failed to capture all $\mathrm{OOH}$ contacts and made overall OOHS use levels difficult to ascertain. ${ }^{14}$ In general, there was little attempt to standardise data reporting across settings-for example, by reporting contact rates per head of population served. While many studies reported on the $\mathrm{OOH}$ period covered, there was often no clear description of the characteristics of the population beyond age and gender. To explore trends in OOHS use we characterised the 40 studies identified in this review that gave OOHS contact rates or reported data from which a contact rate could be calculated (table 2). This was not possible for the remaining 65 papers due to a lack of population denominators, individual patient-level data, duplicate data, in-hours and $\mathrm{OOH}$ contacts combined, or data that were restricted to particular patient groups or face-to-face contacts.

Overall, crude OOHS contact rates by country and year of data collection show no clear trend. Variation within country settings was apparent. For example, analysis of routine data comparing 20 GP cooperatives in England and Scotland showed an overall OOHS contact rate of 159 calls per 1000 patients per year but a rate of 221 calls / 1000/ year in Scotland compared with 45 calls/1000/year in England.$^{15}$ However, variation in OOHS model type, population covered and operational hours by the service made rate comparisons difficult. This heterogeneity in the data collected is described in table $2 .{ }^{15}$ Adjusting for the number of hours covered by OOHS made little difference to the crude contact rates presented in table 2 (data not shown). However, variation in use might be due to more than demographic factors of the population or opening hours of the service; one international comparison suggested cultural differences accounted for more OOHS use in Denmark than in the Netherlands. ${ }^{16}$

More recently, routine electronic data for the entire countries have become available. Data from the national TTA service in Scotland, NHS 24, showed there were 1285038 calls in 2011, with $82 \%$ of calls occurring during $\mathrm{OOH}$ period. ${ }^{17}$ This equated to an OOHS contact rate of roughly 200/1000/year. Country-wide data from Norway explored 


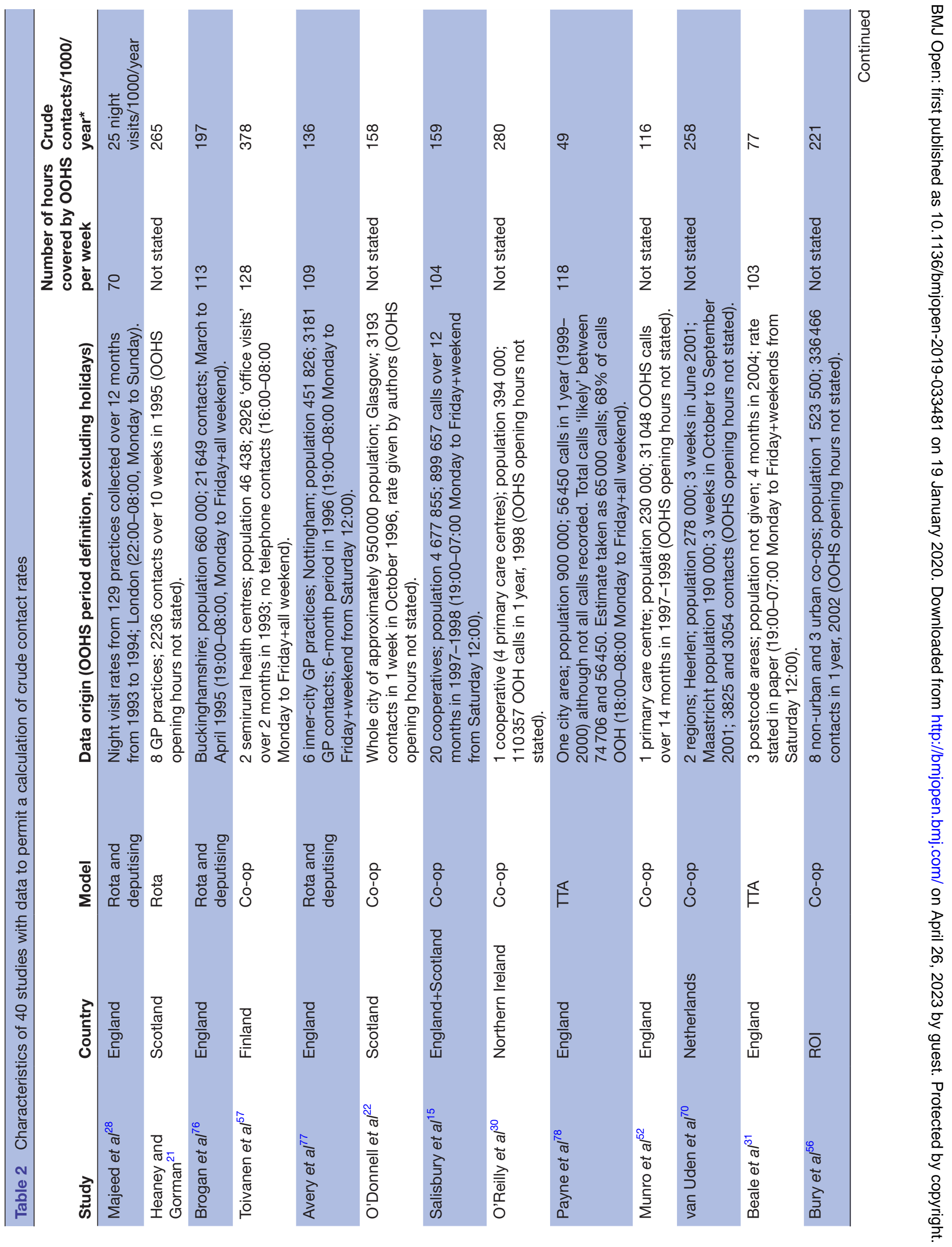




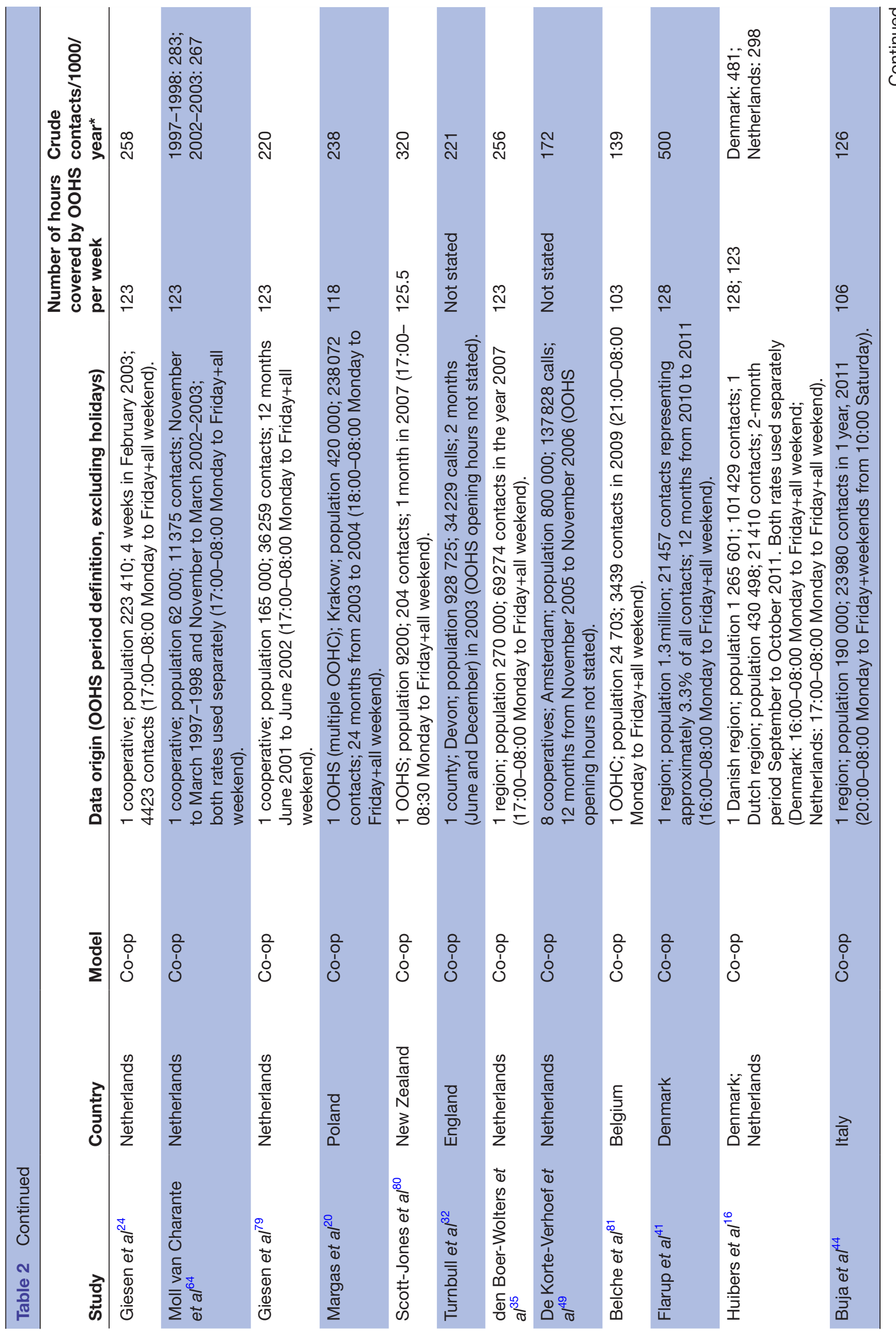




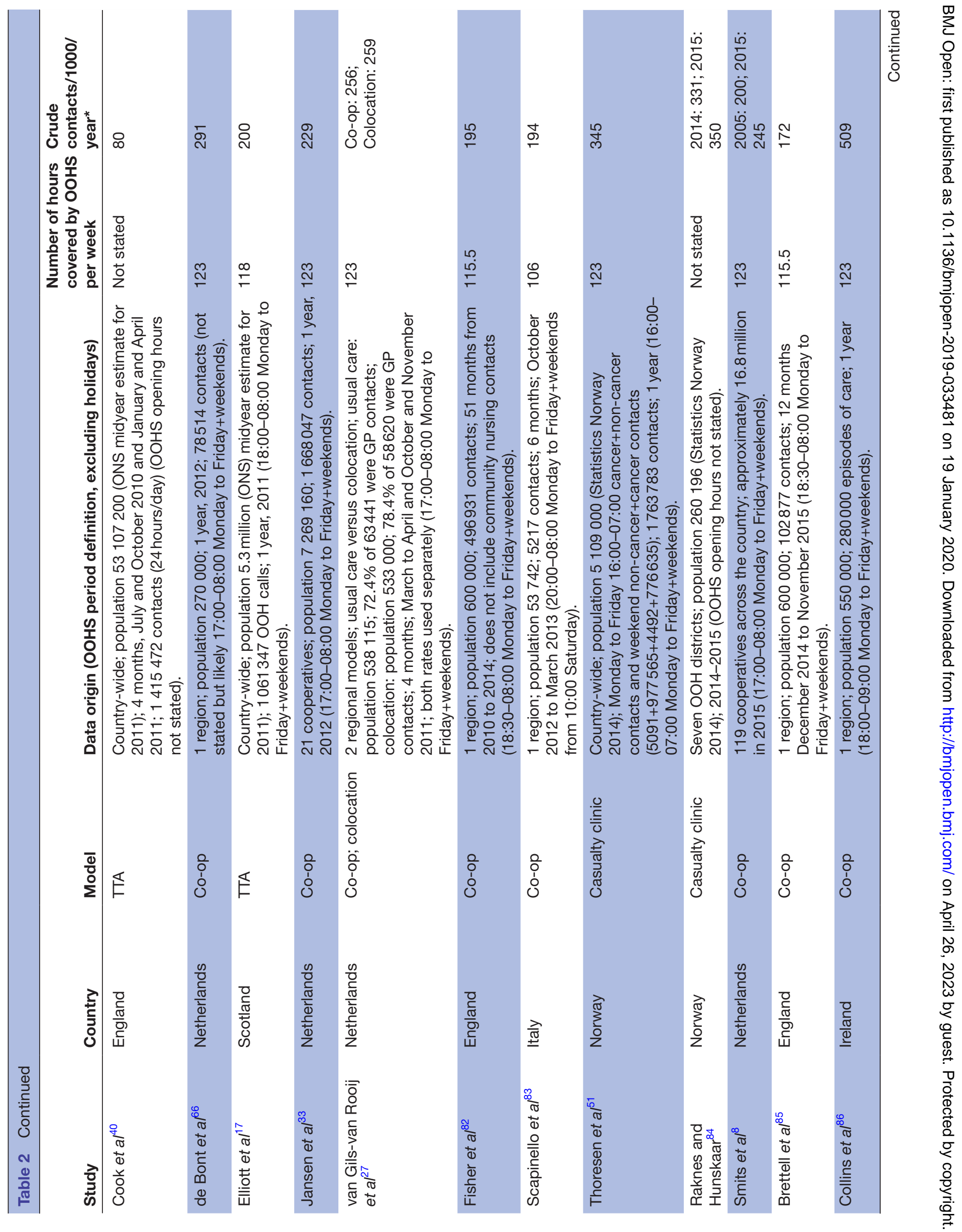




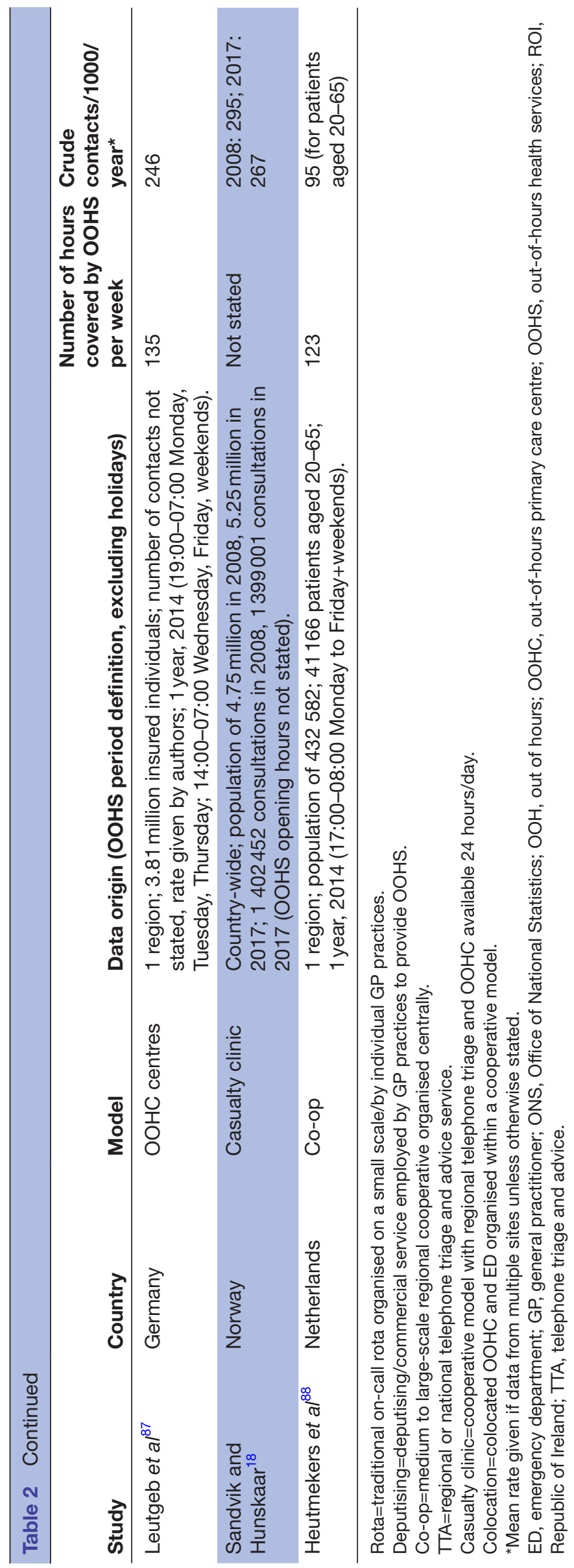

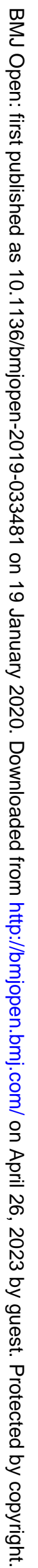


Table 3 Summary of OOHS use patterns, user characteristics associated with increased use and common reason for encounter/presenting condition

\begin{tabular}{|c|c|}
\hline Time of peak use & References \\
\hline Weekday: 18:00-23:00 hours & $\begin{array}{l}1519-212745526476 \\
848990\end{array}$ \\
\hline Weekends>weekdays & $\begin{array}{l}15202132526576 \\
90-93\end{array}$ \\
\hline $\begin{array}{l}\text { Within weekends: Sunday } \\
\text { morning>afternoon/evening }\end{array}$ & 151920 \\
\hline
\end{tabular}

00:00-08:00 hours: weekend>weekday 1521

\begin{tabular}{|c|c|}
\hline \multicolumn{2}{|l|}{ User characteristics } \\
\hline $\begin{array}{l}\text { Age: }<5 \text { years, children }(5-16 \text { years), } \\
\text { and }>65 \text { years most frequent users }\end{array}$ & $\begin{array}{l}15-17 \quad 19-2123252628 \\
30-32383943446576 \\
9094-99\end{array}$ \\
\hline Gender: female>male & $\begin{array}{l}1516181921232426 \\
2731323638394143 \\
4452646567778488 \\
909293959698-101\end{array}$ \\
\hline Socioeconomic status: lower>higher & 1522 28-33 38 \\
\hline Presence of chronic disease & $2835-38$ \\
\hline \multicolumn{2}{|c|}{ Reason for encounter/presenting symptoms } \\
\hline Perceived urgency & 34 40-42 749099102 \\
\hline Symptoms of $<24$ hours' duration & 179293 \\
\hline $\begin{array}{l}\text { Respiratory, skin, abdominal, } \\
\text { musculoskeletal or unspecified } \\
\text { symptoms }\end{array}$ & $\begin{array}{l}17-19253543597081 \\
84899293101103-105\end{array}$ \\
\hline $\begin{array}{l}\text { Infection related (viral, upper } \\
\text { respiratory tract infection (URTI), }\end{array}$ & $\begin{array}{l}1924265964677677 \\
98105106\end{array}$ \\
\hline
\end{tabular}
diarrhoea and vomiting)

\begin{tabular}{ll}
$\begin{array}{l}\text { More mental health problems } \\
\text { compared with in-hours primary care }\end{array}$ & 35 \\
\hline $\begin{array}{l}\text { More severe psychiatric disease } \\
\text { Cancer and palliative care issues, }\end{array}$ & 36384546 \\
including pain and infection & $47-51$ \\
\hline $\begin{array}{l}\text { Geographical proximity and daytime practice } \\
\text { Closer to OOHS>further away from }\end{array}$ & $30323852-54$ \\
OOHS & 5556 \\
$\begin{array}{l}\text { Rural use>urban use } \\
\text { Rural use<urban use }\end{array}$ & 32 \\
$\begin{array}{l}\text { Higher users of daytime services more } \\
\text { likely to use OOHS }\end{array}$ & 378 \\
\hline $\begin{array}{l}\text { Perceived difficulty accessing daytime } \\
\text { services }\end{array}$ & 345960 \\
\hline
\end{tabular}

OOHS, out-of-hours health services.

OOHS use between 2008 and 2017 and found that the number of consultations remained fairly constant at around 1.4 million per year. ${ }^{18}$ However, the rise in the population meant that crude contact rates fell from 295/1000/year in 2008 to $267 / 1000 /$ year in 2017 (table 2).

\section{Time of use and demographics of users}

Many papers reported OOHS use by time of the week. This identified a consistent weekly pattern of peak OOHS use across countries (table 3 ). Weekends were busier than weeknights. During the week, 18:00-23:00 was the busiest period, while Sunday mornings were often the busiest weekend period. ${ }^{151920}$ Night-time contacts (00:00-08:00) were more common at the weekend than during the week. ${ }^{1521}$

Studies which examined the demographics of users found that the most frequent users of OOHS were children, especially those under 5 years old (table 3). Although not always apparent when absolute numbers of contacts were reported, older adults (65 and over) had higher rates of contact than younger adults. ${ }^{15} 162223$ Women tended to use OOHS more than men, but men were more likely than women to use the ED out of hours. ${ }^{23-27}$

Overall, lower socioeconomic status was associated with higher use of OOHS, ${ }^{15} 22$ 28-33 although one study reported that this pattern was reversed for patients aged over $65 .{ }^{22}$ Data from 21 cooperatives in the Netherlands showed neighbourhood characteristics such as household income and socioeconomic status explained some but not all of the variation in OOHS use. ${ }^{33}$ Deprivation also appeared to influence service choice with those from more deprived areas more likely to use ED than OOHS. ${ }^{23}{ }^{29}$ These deprivation effects may be due to increased need, or to reduced access (or perceived reduced access) to daytime services in more deprived areas. ${ }^{34}$ Having a chronic disease was associated with increased use of OOHS, although the chronic disease was often not the reason for contact. ${ }^{2835-38}$

Few studies examined patient ethnicity or migrant status. Of those which did, there appeared to be an association with OOHS use, although the evidence was mixed and studies used various definitions of ethnicity and migrant status. Routine data from 21 Dutch cooperatives showed higher OOHS use in neighbourhoods with more non-Western immigrants ${ }^{33}$ while national data from Norway showed that migrant groups had lower emergency primary care contact rates overall although rates were higher for specific migrant groups. ${ }^{39}$ In England, TTA data found that, following contact with NHS Direct, white British or Bangladeshi children were most likely to be referred to urgent care services including OOHS while children of Indian and 'other white' ethnicity were least likely to be referred. ${ }^{40}$

\section{Urgency and presenting symptoms}

Contact with OOHS was driven by new or evolving problems perceived as urgent both by patients and by telephone triage call handlers (table 3). Perceived urgency or exacerbation of an existing problem was reported as a reason for encounter in OOHS studies from Scotland, ${ }^{34}$ Denmark $^{41}$ and Norway. ${ }^{42}$ Four months of national TTA data from NHS Direct in England showed one in five callers were referred on to urgent care services (ambulance, ED or OOHS) by call handlers and urgent and emergency referrals were more frequent than non-urgent referrals in the $\mathrm{OOH}$ period. ${ }^{40}$ In Scotland, TTA call handlers recorded duration of symptoms for 897903 calls 
(69.9\% of all calls); $62.9 \%$ of these calls concerned symptoms of $<24$ hours' duration. ${ }^{17}$

Eighteen papers reported that respiratory, skin, abdominal, musculoskeletal and unspecified symptoms were common presentations (table 3). Symptoms associated with viral and upper respiratory tract infections, diarrhoea and vomiting also featured in 11 papers. Retrospective data from eight European countries showed consistency across countries in the common presenting symptoms: respiratory (20.4\% of contacts), musculoskeletal $(15.0 \%)$, skin $(12.5 \%)$, abdominal/digestive $(11.6 \%)$, general and unspecified symptoms (13.2\%). ${ }^{43}$ This is supported by TTA data from Scotland where the most common $\mathrm{OOH}$ problems were abdominal symptoms (13.2\%), rashes/ skin conditions $(6.4 \%)$, breathing difficulties $(6.3 \%)$ and genitourinary symptoms $(6.2 \%) .{ }^{17}$ Symptoms varied with age: fever and gastrointestinal symptoms were the most common in children under-5s; cardiovascular disease and gastrointestinal symptoms were the most common in older patients. ${ }^{44}$

Few studies focused on mental health; those that did described an increased prevalence of mental health problems in OOHS populations. ${ }^{35} 38$ The studies also highlighted the higher level of urgency associated with mental health-related OOHS contacts, ${ }^{40}$ and that mental health problems in OOHS were of a greater severity than those in daytime hours. ${ }^{46}$

Five studies focused on cancer and OOHS use. ${ }^{47-51}$ Cancer-related symptoms and palliative care accounted for $2 \%$ of OOHS contacts in two observational studies in the UK. ${ }^{47}{ }^{48}$ Analysis of billing claims in Norway showed contacts by patients with a cancer diagnosis accounted for $1 \%$ of all OOHS contacts in 2014, although only $47.7 \%$ of those contacts were cancer related. ${ }^{51}$ Pain and infection control were the most common reasons for cancerrelated contact in two observational studies. ${ }^{50} 51$

\section{Proximity to $00 \mathrm{HS}$ and relationship with daytime services}

The relationship of proximity to OOHS to use or interactions with daytime GP services were addressed less frequently. Six studies reported that proximity to an OOHS was associated with higher use. $.^{30} 3852-54$ Three studies showed higher rates of OOHS use in more urban areas. ${ }^{32353}$ Conversely, routine data in Ireland found rural cooperatives had higher OOHS use than urban cooperatives. ${ }^{556}$ In Finland, a retrospective review comparing three models of care found that OOHS use was higher where patients were able to attend their local primary care centre during out of hours compared with a model where OOHS access was more centralised. ${ }^{57}$ However, these studies did not adjust for potential confounders such as patient socioeconomic status or need.

Two studies reported that frequent users of daytime services were also frequent users of OOHS ${ }^{37} 58$; three reported that difficulties accessing daytime services were a reason for using OOHS. ${ }^{345960}$ Drummond et al found that these difficulties were associated with patients from lower socioeconomic areas. ${ }^{34}$ Analysis of 100 general practices in the Netherlands found that practices characterised as high users of OOHS were: situated closer to cooperatives; had longer telephone waiting times; had GPs less available for palliative care; performed more tests; had a higher perceived workload; and had more assistants. ${ }^{61}$ However, this study was unable to assess patient health status and did not adjust for socioeconomic status.

One-third of patients contacting OOHS due to a chronic disease exacerbation had a daytime primary care contact in the preceding 30 days. ${ }^{62}$ A study of 210 observed OOHS consultations in Norway found that $18 \%$ of the clinicians' time was taken up with dealing with 'minor ailments' suggesting that improved self-care for minor ailments might reduce OOHS use ${ }^{63}$ Finally, a review of palliative care-related OOHS contacts showed that where information from the daytime GP was available, patients were less likely to be referred by OOHS doctors to hospital, highlighting how communication links with daytime services could influence OOHS care. ${ }^{49}$

\section{OOHS outcomes}

Much of the literature focused on the consultation type after contacting the OOHS, onward referral from the OOHS and outcomes after the contact. Most services offered the option of a home visit, a face-to-face consultation with a GP or other healthcare professional often at a primary care centre, or telephone advice (table 4). Other outcomes included being sent an ambulance or being redirected to an ED. Overall, face-to-face consultations or telephone advice were the most frequent outcomes. However, home visits were much more likely for older patients or patients with cancer or palliative care needs. ${ }^{16172022} 2540415051$ 64-66 Younger patients were more likely to be seen at an $\mathrm{OOH}$ centre or receive telephone advice. $^{202230415051}$

The types of OOHS consultation were associated with geographical distance. Routine data from a cooperative in England found that those who lived further away were less likely to be seen face to face.$^{52}$ In Ireland, urban cooperatives performed fewer home visits and fewer telephone consultations and more centre-based consultations than rural cooperatives. ${ }^{56}$

Several studies identified characteristics associated with face-to-face contacts, onward referral to ED and subsequent contacts or escalation in care. Analysis of 4years' worth of OOHS contacts in one area of England showed that $1 \%$ (4832) of all OOHS contacts had a second OOHS contact within 3 days which resulted in referral to urgent secondary care services (eg, hospital admission, ED or immediate ambulance) ${ }^{67}$ Increasing age, prior use of OOHS and presentation during periods of low contact rates (eg, overnight) were identified as patient factors associated with this 'delayed escalation'. In Denmark, patients with chronic disease had a higher risk of subsequent OOHS or daytime GP contact, hospital admission and mortality during a 30-day follow-up period. ${ }^{62}$ Palliative care patients were also more likely to be referred to hospital by OOHS doctors; this was true across a range 
Table 4 Outcomes of OOHS contact

Outcomes as a \% of OOHS contacts

\begin{tabular}{llllll} 
Study & Service and setting & Home visit & Centre visit & Telephone advice & Oth \\
\cline { 3 - 6 } $\begin{array}{l}\text { Heaney and } \\
\text { Gorman }\end{array}$ & GP rota, Scotland & 63.0 & 8.0 & 29.0 & - \\
Hulland et al $^{94}$ & $\begin{array}{l}\text { GP rota+deputising } \\
\text { service, England }\end{array}$ & - & - & 34.0 & -
\end{tabular}

(children under 5

years only)

\begin{tabular}{|c|c|c|c|c|c|}
\hline O'Donnell et $\left.a\right|^{22}$ & $\begin{array}{l}\text { Cooperative, } \\
\text { Scotland }\end{array}$ & 22.7 & 53.7 & 14.1 & $\begin{array}{l}\text { Sent ambulance: } 2.0 \\
\text { Did not attend: } 4.5\end{array}$ \\
\hline Salisbury et al ${ }^{15}$ & $\begin{array}{l}\text { Cooperatives, } \\
\text { England and } \\
\text { Scotland }\end{array}$ & 23.6 & 29.8 & 45.4 & Other (not stated): 1.2 \\
\hline
\end{tabular}

\begin{tabular}{|c|c|c|c|}
\hline O'Reilly et a/ ${ }^{30}$ & $\begin{array}{l}\text { Cooperative, } \\
\text { Northern Ireland }\end{array}$ & 19.0 & 27.0 \\
\hline $\begin{array}{l}\text { Payne and } \\
\text { Jessopp }^{90}\end{array}$ & $\begin{array}{l}\text { Telephone triage } \\
\text { and advice service, } \\
\text { England }\end{array}$ & & \\
\hline
\end{tabular}

37.0

Directed to GP, either OOHS or daytime: 29.0 Directed to ED: 6.0 Directed to communitybased services: 6.0 Directed to ambulance services: 1.0

\begin{tabular}{|c|c|c|c|c|c|}
\hline Munro et $a^{52}$ & $\begin{array}{l}\text { Cooperative, } \\
\text { England }\end{array}$ & 14.2 & 42.5 & 43.3 & - \\
\hline Pooley et al ${ }^{96}$ & $\begin{array}{l}\text { Cooperatives, } \\
\text { England }\end{array}$ & 36.1 & 29.5 & 34.3 & - \\
\hline van Uden et $a l^{70}$ & $\begin{array}{l}\text { Two cooperatives, } \\
\text { the Netherlands }\end{array}$ & $\begin{array}{l}\text { Site A: } 13.4 \\
\text { Site B: } 7.4\end{array}$ & $\begin{array}{l}\text { Site A: } 47.6 \\
\text { Site B: } 62.8\end{array}$ & $\begin{array}{l}\text { Site A: } 39.0 \\
\text { Site B: } 29.8\end{array}$ & - \\
\hline Bury et $a l^{56}$ & $\begin{array}{l}\text { Eleven cooperatives, } \\
\text { Ireland }\end{array}$ & 12.3 & 53.8 & 34.0 & - \\
\hline $\begin{array}{l}\text { Moll van } \\
\text { Charante et } a l^{64}\end{array}$ & $\begin{array}{l}\text { Cooperative, the } \\
\text { Netherlands }\end{array}$ & 9.4 & 41.7 & 36.6 & - \\
\hline $\begin{array}{l}\text { Hansen and } \\
\text { Hunskaar }\end{array}$ & $\begin{array}{l}\text { Cooperative casualty } \\
\text { clinics, Norway }\end{array}$ & 1.9 & 62.2 & 29.9 & $\begin{array}{l}\text { Call-out of GP and } \\
\text { ambulance: } 2.1 \\
\text { Other: } 3.9\end{array}$ \\
\hline Hansen et $a l^{65}$ & $\begin{array}{l}\text { Cooperative casualty } \\
\text { clinics, Norway }\end{array}$ & 3.3 & 62.7 & 9.5 & $\begin{array}{l}\text { Dealt with by nurses } \\
\text { only: } 24.0\end{array}$ \\
\hline Eichler et al $1^{103}$ & $\begin{array}{l}\text { Cooperative, } \\
\text { Switzerland }\end{array}$ & 61.3 & 24.8 & 13.9 & - \\
\hline Philips et $a l^{25}$ & $\begin{array}{l}\text { Cooperative, } \\
\text { Belgium }\end{array}$ & $\begin{array}{l}\text { Pre co-op: } 27.0 \\
\text { Post co-op: } 16.0\end{array}$ & $\begin{array}{l}\text { Pre co-op: } 73.0^{\star} \\
\text { Post co-op: } 84.0^{*}\end{array}$ & - & $\begin{array}{l}{ }^{*} \mathrm{GP} \text { consultation- } \\
\text { unclear if face-to- } \\
\text { face, or if telephone } \\
\text { consultation included }\end{array}$ \\
\hline
\end{tabular}


Table 4 Continued

\begin{tabular}{|c|c|c|c|c|c|}
\hline \multirow[b]{2}{*}{ Study } & \multirow[b]{2}{*}{ Service and setting } & \multicolumn{4}{|c|}{ Outcomes as a \% of OOHS contacts } \\
\hline & & Home visit & Centre visit & Telephone advice & Other \\
\hline Johansen et al ${ }^{45}$ & $\begin{array}{l}\text { Cooperative } \\
\text { 'casualty clinics', } \\
\text { Norway }\end{array}$ & 0.9 & 62.6 & 9.1 & $\begin{array}{l}\text { Emergency call-out of } \\
\text { GP: } 1.8 \\
\text { Telephone advice from } \\
\text { nurse: } 18.2 \\
\text { Nurse consultation: } 1.7 \\
\text { Other: } 5.7\end{array}$ \\
\hline Flarup et $a l^{41}$ & $\begin{array}{l}\text { Cooperatives, } \\
\text { Denmark }\end{array}$ & 9.2 & 19.8 & 42.1 & $\begin{array}{l}\text { Telephone referrals to } \\
\text { other services: } 28.9\end{array}$ \\
\hline Buja et al ${ }^{44}$ & OOHS, Italy & $52.1^{*}$ & * & 37.9 & $\begin{array}{l}\text { *Home visits and centre } \\
\text { visits combined } \\
\text { Referred to ED: } 9.2 \\
\text { Referred to other } \\
\text { specialist: } 0.8\end{array}$ \\
\hline Cook et $a l^{40}$ & $\begin{array}{l}\text { Telephone triage and } \\
\text { advice line, England } \\
\text { (in-hours and out-of- } \\
\text { hours period) }\end{array}$ & - & - & - & $\begin{array}{l}\text { Urgent redirect to } \\
\text { ambulance service: } 3.5 \\
\text { Urgent redirect to A\&E: } \\
8.6 \\
\text { Urgent redirect to GP } \\
\text { service: } 7.3 \\
\text { Non-urgent redirect to } \\
\text { GP service: } 9.9 \\
\text { See GP on same day: } \\
12.1 \\
\text { Self-care advice: } 27.9 \\
\text { Health or dental: } 14.5 \\
\text { Other: } 16.2\end{array}$ \\
\hline de Bont et $a l^{66}$ & $\begin{array}{l}\text { Cooperative, the } \\
\text { Netherlands } \\
\text { (contacts for fever in } \\
\text { children only) }\end{array}$ & - & 70.0 & 30.0 & - \\
\hline Elliott et $a^{17}$ & $\begin{array}{l}\text { Telephone triage } \\
\text { and advice service, } \\
\text { Scotland } \\
\text { (out-of-hours period } \\
\text { only) }\end{array}$ & 12.2 & 34.1 & 10.2 & $\begin{array}{l}\text { Ambulance called: } 6.9 \\
\text { Advised/sent to ED: } 5.8 \\
\text { Advised to contact } \\
\text { daytime GP: } 8.4 \\
\text { Advised to contact } \\
\text { pharmacist: } 2.3 \\
\text { Other: } 20.2\end{array}$ \\
\hline $\begin{array}{l}\text { van Gils-van } \\
\text { Rooij et al }\end{array}$ & $\begin{array}{l}\text { Urgent care } \\
\text { collaboratives (UCC), } \\
\text { the Netherlands }\end{array}$ & 5.1 & 43.8 & 29.5 & Treatment at ED: 21.6 \\
\hline Gnani et al ${ }^{105}$ & $\begin{array}{l}\text { Urgent care centres, } \\
\text { England } \\
\text { (preschool children) }\end{array}$ & - & - & - & $\begin{array}{l}\text { Discharged home after } \\
\text { attendance: } 40.0 \\
\text { Discharged home with } \\
\text { GP follow-up: } 39.0 \\
\text { Referred to specialist: } \\
11.0 \\
\text { Referred to ED: } 8.0 \\
\text { Other: } 2.0\end{array}$ \\
\hline
\end{tabular}


Table 4 Continued

\begin{tabular}{|c|c|c|c|c|c|}
\hline \multirow[b]{2}{*}{ Study } & \multirow[b]{2}{*}{ Service and setting } & \multicolumn{4}{|c|}{ Outcomes as a \% of OOHS contacts } \\
\hline & & Home visit & Centre visit & Telephone advice & Other \\
\hline Huibers et al ${ }^{92}$ & OOHS, Denmark & - & $40.8^{*}$ & 59.2 & $\begin{array}{l}{ }^{*} \text { Unclear if this includes } \\
\text { both home visits and } \\
\text { centre attendances }\end{array}$ \\
\hline Thoresen et al ${ }^{51}$ & $\begin{array}{l}\text { Cooperative casualty } \\
\text { clinics, Norway } \\
\text { (focus on patients } \\
\text { with cancer) }\end{array}$ & $\begin{array}{l}\text { Patients with } \\
\text { cancer: } 3.1 \\
\text { Non-cancer } \\
\text { patients: } 14.2\end{array}$ & $\begin{array}{l}\text { Patients with } \\
\text { cancer: } 42.4 \\
\text { Non-cancer } \\
\text { patients: } 67.0\end{array}$ & $\begin{array}{l}\text { Patients with } \\
\text { cancer: } 26.7 \\
\text { Non-cancer } \\
\text { patients: } 24.3\end{array}$ & $\begin{array}{l}\text { Simple contacts (no } \\
\text { definition given) } \\
\text { Patients with cancer: } \\
2.6 \\
\text { Non-cancer patients: } \\
2.2 \\
\text { Nursing service } \\
\text { Patients with cancer: } \\
2.6 \\
\text { Non-cancer patients: } \\
2.2\end{array}$ \\
\hline Smits et $a l^{8}$ & $\begin{array}{l}\text { Cooperatives, the } \\
\text { Netherlands }\end{array}$ & 10.0 & 50.0 & 40.0 & - \\
\hline Brettell et al ${ }^{85}$ & $\begin{array}{l}\text { OOHS, England } \\
\text { (focus on patients } \\
\text { who died within } 30 \\
\text { days of contact) }\end{array}$ & $\begin{array}{l}\text { Died within } 30 \\
\text { days: } 55.8 \\
\text { Alive within } 30 \\
\text { days: } 9.7\end{array}$ & $\begin{array}{l}\text { Died within } 30 \\
\text { days: } 4.2 \\
\text { Alive within } 30 \\
\text { days: } 55.8\end{array}$ & $\begin{array}{l}\text { Died within } 30 \\
\text { days: } 39.9 \\
\text { Alive within } 30 \\
\text { days: } 34.3\end{array}$ & - \\
\hline
\end{tabular}

A\&E, accident and emergency; ED, emergency department; GP, general practitioner; OOHS, out-of-hours health services.

of palliative conditions including cancer, cardiovascular disease, digestive and endocrine problems. ${ }^{49} 586263$

\section{Wider impact of new models of 00HS care}

OOHS service reforms leading to the formation of GP cooperatives and primary care centres led to marked changes in consultation types within geographical areas, in particular the development of patient visits to centres, TTA and a decrease in home visits. ${ }^{3514}$ There was little evidence that reforms to OOHS led to higher use of EDs. Routine data of OOHS and ED use from one region in the Netherlands over 4 weeks before and after the introduction of three OOHS cooperatives showed a $9 \%$ decrease in ED contacts and a $10 \%$ increase in OOHS contacts. ${ }^{68}$ Similarly, routine data from a single cooperative and ED in Maastricht, the Netherlands, showed that after introduction of a cooperative ED use dropped by $53 \%$ and OOHS use increased by $25 \% .^{69}$

More recently, evaluation of Dutch Urgent Care Collaborations, in which OOHS are colocated with EDs, reported mixed results. One study found no significant difference in ED contact rates but significantly fewer telephone consultations and home visits and more centre visits at the colocated OOHC..$^{70}$ In another evaluation, GPs dealt with a significantly higher proportion of patients and fewer patients ended up being seen in the ED, compared with separate OOHS and EDs. ${ }^{27}$ Furthermore, within a colocated OOHS and ED, non-urgent ED contacts received more tests and more follow-up contacts than non-urgent OOHS contacts. ${ }^{71}$ This might suggest improved efficiency at colocated OOHS and EDs with fewer patients inappropriately diverted to ED. However, these studies did not include quality of care measures or patient perspectives, so it is difficult to corroborate this assertion. ${ }^{27}$

A prospective case review following introduction of a TTA service in three areas in England showed minimal impact on ED and ambulance services and a small reduction in OOHS use. ${ }^{72}$ Routine data analysis from Denmark showed that OOHS reform to regional cooperatives was not associated with significant change in ED contact rates. ${ }^{73}$ However, there was some evidence for inappropriate ED use after OOHS reform and that OOHS organisations could reduce ED workload. For example, after 
implementation of new OOHS arrangements in England, a survey of 200 patients admitted via ED to an innercity hospital showed that although most patients sought primary care advice prior to attending $\mathrm{ED}$, a significant minority attended ED directly and there was incomplete awareness of the new OOHS arrangements. ${ }^{74}$ A systematic review of 74 studies identified barriers and facilitators of successful implementation of OOHS models that reduced ED workload. The review cited evidence for: TTA response delays increasing ambulance demand; extended paramedic roles reducing ED demand; and colocation and integration of GP and ED services reducing cost and ED workload. ${ }^{75}$

\section{DISCUSSION}

We present here a major update to the literature on OOHS demand, use and outcomes. This literature was predominately observational and cross-sectional, drawing on data collected by the services themselves and originating in UK or western European countries. The literature documents the impact of the widespread policy change in OOHS organisation from smaller, rota-based models to larger, more centralised OOHS models, the development of telephone-based triage and advice lines and colocation of OOHS with EDs. Although there is a generally agreed definition of the $\mathrm{OOH}$ period internationally, a lack of comparable collected data (eg, by defining the denominator population or the time frame) means that it is difficult to reliably track demand over time, even within countries. Thus, there is a lack of clear evidence to support claims that demand for OOHS is increasing or that OOHS use has been affected by new models of care. A general absence of contextual data on the setting and/or population served also means that variations in demand across OOHS are difficult to explain. We suggest, therefore, that rather than continuing to collect data on demand, some effort is first put into defining what data should be collected, and by whom, to allow robust comparisons within and across countries.

We did, however, identify clear and consistent patterns of peak OOHS use as well as population groups who are more frequent OOHS users: young children, older adults, women, as well as those with chronic diseases or mental health problems. However, the reason for the actual contact with the OOHS was often unrelated to the chronic illness itself. There was also clear descriptive evidence for the common symptoms and reasons for which people contact OOHS including perceived urgency and infection-related symptoms and these reasons tend to differ from those attending ED out of hours. However, evidence using accurate diagnostic coding for conditions presenting during out of hours is non-existent. Linking high-quality data from OOHS, hospital discharge and daytime primary care could, therefore, generate more definitive diagnostic data that could aid service planning.

Descriptive data here show that palliative-related contacts may account for relatively few numbers of
OOHS contacts $(1 \%-2 \%)$. However, such contacts were associated with a high rate of home visits; thus although the overall numbers are small, the workload generated is large. The effects of deprivation, distance and rurality on OOHS use highlight the importance of incorporating local sociodemographic variables into OOHS design. Similarly, the effect of culture on OOHS use means that comparisons across countries need to take into account cultural differences as well as structural service differences in order for comparisons to be meaningful.

OOHS reforms and organisational changes led to new types of care being offered to patients, including face-toface contacts in primary care centres and an increasing use of TTA. However, there was a lack of evidence for an effect of OOHS models on overall OOHS use. There was mixed evidence of the effect of OOHS models on ED use but policy reform towards a colocated model seemed to reduce ED demand. The potential impact that different models of care can have on OOHS use means that new models should be piloted and their impact on other health services evaluated prior to national roll-out. Moreover, the literature highlighted the inter-related nature of daytime services and OOHS. Future developments should, we suggest, pay more attention to this relationship and consider how changes in one setting may impact on care provision in the other setting. In particular, the literature offered observational evidence of opportunities for daytime primary care contacts to reduce OOHS through enhanced chronic disease management and anticipatory palliative care, however there is a lack of experimental evidence of enhancing daytime care to influence OOHS use. However, such developments must be mindful of those who are disadvantaged in terms of healthcare access, and so ensure that health inequalities are not exacerbated.

\section{CONCLUSION}

There is a large, international body of quantitative, observational and cross-sectional literature documenting the demand, use and outcomes of OOHS. Changes in patient use of OOHS have been driven by new models of care developed as a result of changes to $\mathrm{OOH}$ primary care policy. A lack of internationally agreed standards in data collection and service definitions means that comparison of service demand across and within countries is difficult and makes it difficult to ascertain how that demand is changing; however, there are consistencies with respect to the demographics and presenting symptoms of those who use OOHS. Moving forward, there is an urgent need for robust evaluations of the new models of care being developed, particularly in relation to the OOHS-ED interface and more consideration of how demand in daytime services impacts on OOHS and vice versa.

Twitter Catherine A 0'Donnell @odo_kate

Contributors $C A O^{\prime} D, H F$ and SM conceived the idea and designed the study. $\mathrm{CAO}$ 'D, NB, MG and SMCD designed and conducted the search strategies, with 
input from the University of Glasgow and Health Improvement Scotland subjectspecific librarians. All authors (HF, KRM, NB, MG, SM and CAO'D) contributed to the design of data extraction proformas, screening of titles, abstracts and papers, and data extraction. HF, KRM and CAO'D analysed the data. All authors contributed to data interpretation. HF wrote the first draft. CAO'D led the redrafting. All authors contributed to the final version and agreed to its submission. CAO'D is the guarantor of this study.

Funding This study was funded by the Scottish Government through the Primary Care Division and Health Improvement Scotland.

Competing interests None declared.

Patient consent for publication Not required.

Provenance and peer review Not commissioned; externally peer reviewed.

Data availability statement Data are available upon reasonable request. Copies of the search strategy, identified studies and data extraction proforma are available on request to $\mathrm{HF}$ or $\mathrm{CAO} D$.

Open access This is an open access article distributed in accordance with the Creative Commons Attribution Non Commercial (CC BY-NC 4.0) license, which permits others to distribute, remix, adapt, build upon this work non-commercially, and license their derivative works on different terms, provided the original work is properly cited, appropriate credit is given, any changes made indicated, and the use is non-commercial. See: http://creativecommons.org/licenses/by-nc/4.0/.

ORCID iD

Catherine A 0'Donnell http://orcid.org/0000-0002-5368-3779

\section{REFERENCES}

1 BMA General Practitioners Committee. The new GMS contract explained. Focus on...Out of hours, 2003. Available: http:// wwwbmaorguk/asnsf/Content/focusooh

2 Berchet C, Nader C. The organisation of out-of-hours primary care in OECD countries. OECD Publishing, 2016.

3 Christensen MB, Olesen F. Out of hours service in Denmark: evaluation five years after reform. BMJ 1998;316:1502-5.

4 van Uden CJT, Giesen PHJ, Metsemakers JFM, et al. Development of out-of-hours primary care by general practitioners (GPs) in the Netherlands: from small-call rotations to large-scale GP cooperatives. Fam Med 2006;38:565-9.

5 O'Donnell CA, Drummond N, Ross S. Out of hours primary care: a critical overview of current knowledge. Health Bull 1999;57:276-84.

6 Tan S, Mays N. Impact of initiatives to improve access to, and choice of, primary and urgent care in the England: a systematic review. Health Policy 2014;118:304-15.

7 Lattimer V, Peckham S, George S. The impact of changing workforce patterns in emergency and urgent out-of-hours care on patient experience, staff practice and health system performance. London, 2010.

8 Smits M, Rutten M, Keizer E, et al. The development and performance of after-hours primary care in the Netherlands: a narrative review. Ann Intern Med 2017;166:737-42.

9 The Scottish Government. Pulling together: transforming urgent care for the people of Scotland. The report of the independent review of primary care out of hours services: national review of Priary care out of hours services. A Scottish government commisioned report. The Scottish Government, 2015.

10 Arksey H, O'Malley L. Scoping studies: towards a methodological framework. Int J Soc Res Methodol 2005;8:19-32.

11 Levac D, Colquhoun H, O'Brien KK. Scoping studies: advancing the methodology. Implement Sci 2010;5.

12 Peters MDJ, Godfrey CM, Khalil H, et al. Guidance for conducting systematic scoping reviews. Int J Evid Based Healthc 2015;13:141-6.

13 Kelly SE, Moher D, Clifford TJ. Quality of conduct and reporting in rapid reviews: an exploration of compliance with PRISMA and AMSTAR guidelines. Syst Rev 2016;5:1-19.

14 Salisbury C. The demand for out-of-hours care from GPs: a review. Fam Pract 2000;17:340-7.

15 Salisbury C, Trivella M, Bruster S. Demand for and supply of out of hours care from general practitioners in England and Scotland: observational study based on routinely collected data. BMJ 2000;320:618-21

16 Huibers L, Moth G, Andersen M, et al. Consumption in out-ofhours health care: Danes double Dutch? Scand J Prim Health Care 2014;32:44-50.
17 Elliott AM, McAteer A, Heaney D, et al. Examining the role of Scotland's telephone advice service (NHS 24) for managing health in the community: analysis of routinely collected NHS 24 data. BMJ Open 2015;5:e007293.

18 Sandvik H, Hunskaar S. Frequent attenders at primary care outof-hours services: a registry-based observational study in Norway. BMC Health Serv Res 2018;18:492.

19 Shipman C, Longhurst S, Hollenbach F, et al. Using out-of-hours services: general practice or A\&E? Fam Pract 1997;14:503-9.

20 Margas G, Windak A, Tomasik T. Utilization of the out of hours service in Poland: an observational study from Krakow. BMC Health Serv Res 2008:8:212.

21 Heaney D, Gorman D. Auditing out-of-hours primary medical care. Health Bulletin 1996;54:495-7.

22 O'Donnell CA, McConnachie A, Moffat K, et al. Cross sectional study of social variation in use of an out of hours patient transport service. BMJ 1999;318:566-7.

23 Willems S, Peersman W, De Maeyer P, et al. The impact of neighborhood deprivation on patients' unscheduled out-of-hours healthcare seeking behavior: a cross-sectional study. BMC Fam Pract 2013;14:136.

24 Giesen P, Franssen E, Mokkink H, et al. Patients either contacting a general practice cooperative or accident and emergency department out of hours: a comparison. Emerg Med J 2006;23:731-4.

25 Philips H, Remmen R, Van Royen P, et al. What's the effect of the implementation of general practitioner cooperatives on caseload? prospective intervention study on primary and secondary care. BMC Health Serv Res 2010;10:222.

26 Chmiel C, Huber CA, Rosemann T, et al. Walk-ins seeking treatment at an emergency department or general practitioner out-of-hours service: a cross-sectional comparison. BMC Health Serv Res 2011:11:94.

27 van Gils-van Rooij ESJ, Yzermans CJ, Broekman SM, et al. Out-OfHours care collaboration between general practitioners and hospita emergency departments in the Netherlands. J Am Board Fam Med 2015;28:807-15.

28 Majeed FA, Cook DG, Hilton S, et al. Annual night visiting rates in 129 general practices in one family health services authority: association with patient and general practice characteristics. $\mathrm{Br} \mathrm{J}$ Gen Pract 1995:45:531-5.

29 Carlisle R, Groom LM, Avery AJ, et al. Relation of out of hours activity by general practice and accident and emergency services with deprivation in Nottingham: longitudinal survey. BMJ 1998;316:520-3.

30 O'Reilly D, Stevenson M, McCay C, et al. General practice out-ofhours service, variations in use and equality in access to a doctor: a cross-sectional study. Br J Gen Pract 2001;51:625-9.

31 Beale N, Taylor G, Gwynne M, et al. Council Tax valuation bands and contacts with a GP out-of-hours service. Br J Gen Pract 2006;56:283-5.

32 Turnbull J, Martin D, Lattimer V, et al. Does distance matter? geographical variation in GP out-of-hours service use: an observational study. Br J Gen Pract 2008;58:471-7.

33 Jansen T, Zwaanswijk M, Hek K, et al. To what extent does sociodemographic composition of the neighbourhood explain regional differences in demand of primary out-of-hours care: a multilevel study. BMC Fam Pract 2015;16:54.

34 Drummond N, McConnachie A, O'Donnell CA, et al. Social variation in reasons for contacting general practice out-of-hours: implications for daytime service provision? Br J Gen Pract 2000;50:460-4.

35 den Boer-Wolters D, Knol MJ, Smulders K, et al. Frequent attendance of primary care out-of-hours services in the Netherlands: characteristics of patients and presented morbidity. Fam Pract 2010;27:129-34.

36 Flarup L, Moth G, Christensen MB, et al. Chronic-disease patients and their use of out-of-hours primary health care: a cross-sectional study. BMC Fam Pract 2014;15:114.

37 Flarup L, Moth G, Christensen MB, et al. Daytime use of general practice and use of the out-of-hours primary care service for patients with chronic disease: a cohort study. BMC Fam Pract 2014;15:156.

38 Buja A, Toffanin R, Rigon S, et al. What determines frequent attendance at out-of-hours primary care services? Eur $J$ Public Health 2015;25:563-8.

39 Sandvik H, Hunskaar S, Diaz E. Immigrants' use of emergency primary health care in Norway: a registry-based observational study. BMC Health Serv Res 2012;12:308.

40 Cook EJ, Randhawa G, Guppy A, et al. A study of urgent and emergency referrals from NHS direct within England. BMJ Open 2015;5:e007533. 
41 Flarup L, Moth G, Christensen MB, et al. A feasible method to study the Danish out-of-hours primary care service. Dan Med J 2014;61:A4847.

42 Zakariassen E, Hansen EH, Hunskaar S. Incidence of emergency contacts (red responses) to Norwegian emergency primary healthcare services in 2007--a prospective observational study. Scand J Trauma Resusc Emerg Med 2009;17:30.

43 Huibers LAMJ, Moth G, Bondevik GT, et al. Diagnostic scope in out-of-hours primary care services in eight European countries: an observational study. BMC Fam Pract 2011;12:30.

44 Buja A, Toffanin R, Rigon S, et al. Out-of-hours primary care services: demands and patient referral patterns in a Veneto region (Italy) local health authority. Health Policy 2015;119:437-46.

45 Johansen IH, Morken T, Hunskaar S. How Norwegian casualty clinics handle contacts related to mental illness: a prospective observational study. Int J Ment Health Syst 2012;6:3

46 Johansen IH, Morken T, Hunskaar S. Contacts related to mental illness and substance abuse in primary health care: a crosssectional study comparing patients' use of daytime versus out-of-hours primary care in Norway. Scand J Prim Health Care 2010;28:160-5.

47 Burt J, Barclay S, Marshall N, et al. Continuity within primary palliative care: an audit of general practice out-of-hours cooperatives. J Public Health (Oxf) 2004;26:275-6.

48 Richards SH, Winder R, Seamark D, et al. Accessing out-ofhours care following implementation of the GMS contract: an observational study. Br J Gen Pract 2008;58:331-8.

49 De Korte-Verhoef MC, Pasman HRW, Schweitzer BPM, et al. End Of-Life Hospital referrals by out-of-hours general practitioners: a retrospective chart study. BMC Fam Pract 2012;13:89.

50 Adam R, Wassell P, Murchie P. Why do patients with cancer access out-of-hours primary care? A retrospective study. Br J Gen Pract 2014;64:e99-104.

51 Thoresen CK, Sandvik H, Hunskaar S. Cancer patients' use of primary care out-of-hours services: a cross-sectional study in Norway. Scand J Prim Health Care 2016;34:232-9.

52 Munro J, Maheswaran R, Pearson T. Response to requests for general practice out of hours: geographical analysis in North West England. J Epidemiol Community Health 2003;57:673-4.

53 Turnbull J, Pope C, Martin D, et al. Do telephones overcome geographical barriers to general practice out-of-hours services? mixed-methods study of parents with young children. J Health Serv Res Policy 2010;15:21-7.

54 Raknes G, Hansen EH, Hunskaar S. Distance and utilisation of outof-hours services in a Norwegian urban/rural district: an ecological study. BMC Health Serv Res 2013;13:222

55 Murphy A, O'hanlon C, Keown DM, et al. Do rural GPs have more out-of-hours patient consultations? Eur J Gen Pract 2001;7:75-6.

56 Bury G, Dowling J, Janes D. General practice out-of-hours cooperatives--population contact rates. Ir Med J 2006;99:73-5.

57 Toivanen A, Rautava P, Kvist M. Out-Of-Hours utilization in primary and secondary care. A favourable experience in a Finnish health centre. Scand J Prim Health Care 1998;16:72-5.

58 Vedsted P, Sørensen HT, Nielsen JN, et al. The association between daytime attendance and out-of-hours frequent attendance among adult patients in general practice. $\mathrm{Br} J \mathrm{Gen}$ Pract 2001;51:121-4.

59 Plauth AE, Pearson SD. Discontinuity of care: urgent care utilization within a health maintenance organization. Am J Manag Care 1998:4:1531-7.

60 Zhou Y, Abel G, Warren F, et al. Do difficulties in accessing in-hours primary care predict higher use of out-of-hours GP services? Evidence from an English national patient survey. Emerg Med $J$ 2015;32:373-8.

61 Smits M, Peters Y, Broers S, et al. Association between general practice characteristics and use of out-of-hours GP cooperatives. BMC Fam Pract 2015;16:52.

62 Flarup L, Carlsen AH, Moth G, et al. The 30-day prognosis of chronic-disease patients after contact with the out-of-hours service in primary healthcare. Scand J Prim Health Care 2014;32:208-16.

63 Welle-Nilsen LK, Morken T, Hunskaar S, et al. Minor ailments in outof-hours primary care: an observational study. Scand J Prim Health Care 2011;29:39-44.

64 Moll van Charante EP, van Steenwijk-Opdam PCE, Bindels PJE. Out-Of-Hours demand for GP care and emergency services: patients' choices and referrals by general practitioners and ambulance services. BMC Fam Pract 2007:8:46.

65 Hansen EH, Zakariassen E, Hunskaar S. Sentinel monitoring of activity of out-of-hours services in Norway in 2007: an observational study. BMC Health Serv Res 2009;9:123.
66 de Bont EGPM, Lepot JMM, Hendrix DAS, et al. Workload and management of childhood fever at general practice out-of-hours care: an observational cohort study. BMJ Open 2015;5:e007365.

67 Hayward GN, Vincent C, Lasserson DS. Predicting clinical deterioration after initial assessment in out-of-hours primary care: a retrospective service evaluation. $\mathrm{Br} J$ Gen Pract 2017;67:e78-85.

68 van Uden CJT, Crebolder H. Does setting up out of hours primary care cooperatives outside a hospital reduce demand for emergency care? Emergency Medicine Journal 2004;21:722-3.

69 van Uden CJT, Winkens RAG, Wesseling G, et al. The impact of a primary care physician cooperative on the caseload of an emergency department: the Maastricht integrated out-of-hours service. J Gen Intern Med 2005;20:612-7.

70 van Uden CJT, Winkens RAG, Wesseling GJ, et al. Use of out of hours services: a comparison between two organisations. Emerg Med J 2003;20:184-7.

71 Huibers L, Thijssen W, Koetsenruijter J, et al. GP cooperative and emergency department: an exploration of patient flows. J Eval Clin Pract 2013;19:243-9.

72 Munro J, Nicholl J, O'Cathain A, et al. Impact of NHS direct on demand for immediate care: observational study. BMJ 2000;321:150-3.

73 Vedsted P, Christensen MB. The effect of an out-of-hours reform on attendance at casualty wards. The Danish example. Scand J Prim Health Care 2001;19:95-8.

74 Benger JR, Jones V. Why are we here? A study of patient actions prior to emergency hospital admission. Emerg Med $\mathrm{J}$ 2008;25:424-7.

75 Fry MM. Barriers and facilitators for successful after hours care model implementation: reducing ED utilisation. Australas Emerg Nurs J 2009;12:137-44.

76 Brogan C, Pickard D, Gray A, et al. The use of out of hours health services: a cross sectional survey. BMJ 1998;316:524-7.

77 Avery A, Groom L, Boot D, et al. What problems do patients present with outside normal general practice surgery hours? A prospective study of the use of general practice and accident and emergency services. J Public Health 1999;21:88-94.

78 Payne F, Shipman C, Dale J. Patients' experiences of receiving telephone advice from a GP co-operative. Fam Pract 2001;18:156-60.

79 Giesen P, Mokkink H, Hensing M, et al. Rude or aggressive patient behaviour during out-of-hours GP care: challenges in communication with patients. Patient Educ Couns 2008;73:205-8.

80 Scott-Jones J, Lawrenson R, Maxwell N. Sharing after hours care in a rural New Zealand community--a service utilization survey. Rural Remote Health 2008;8:1024.

81 Belche JL, Berrewaerts MA, Burette P, et al. Retrospective analysis of a suburban out-of-hours clinic in Belgium. Acta Clin Belg 2014;69:341-7.

82 Fisher RF, Lasserson D, Hayward G. Out-Of-Hours primary care use at the end of life: a descriptive study. Br J Gen Pract 2016;66:e654-60.

83 Scapinello MP, Posocco A, De Ronch I, et al. Predictors of emergency department referral in patients using out-of-hours primary care services. Health Policy 2016;120:1001-7.

84 Raknes G, Hunskaar S. Reasons for encounter by different levels of urgency in out-of-hours emergency primary health care in Norway: a cross sectional study. BMC Emerg Med 2017;17:19.

85 Brettell R, Fisher R, Hunt $\mathrm{H}$, et al. What proportion of patients at the end of life contact out-of-hours primary care? A data linkage study in Oxfordshire. BMJ Open 2018;8:e020244.

86 Collins C, O'Shea MT, Cunniffe J, et al. Health system changes needed to support people consulting general practice out of hours services in Ireland. Int J Ment Health Syst 2018;12:56.

87 Leutgeb R, Berger S, Szecsenyi J, et al. Patients with somatoform disorders: more frequent attendance and higher utilization in primary out-of-hours care? PLoS One 2018;13:e0202546.

88 Heutmekers M, Naaldenberg J, Verheggen SA, et al. Health problems of people with intellectual disabilities in Dutch out-ofhours primary care. J Appl Res Intellect Disabil 2019;32:475-81.

89 Kljakovic M, Dalziel S. Out-Of-Hours attendance and outcomes for asthmatic patients at two primary care services. $N Z$ Med J 1996;109:254-7.

90 Payne F, Jessopp L. NHS direct: review of activity data for the first year of operation at one site. J Public Health 2001;23:155-8.

91 Haith-Cooper M, Stacey T, Edwards E, et al. Pregnancy-Related telephone consultations to an out-of-hours provider: a retrospective study. Primary Health Care 2015;25:24-9.

92 Huibers L, Moth G, Carlsen AH, et al. Telephone triage by GPs in out-of-hours primary care in Denmark: a prospective observational 
study of efficiency and relevance. British Journal of General Practice 2016;66:e667-73.

93 Seeger I, Kreienmeyer L, Hoffmann F, et al. Cross-sectional study in an out-of-hours primary care centre in northwestern Germany patient characteristics and the urgency of their treatment. BMC Fam Pract 2019;20:41

94 Hulland J, Avery AJ, Groom L, et al. Use of primary health care and accident and emergency (emergency department) services for children under 5 years outside normal office hours. Ambulatory Child Health 1999;5:323-30.

95 Vedsted P, Olesen F. Frequent attenders in out-of-hours general practice care: attendance prognosis. Fam Pract 1999;16:283-8.

96 Pooley CG, Briggs J, Gatrell T, et al. Contacting your GP when the surgery is closed: issues of location and access. Health Place 2003;9:23-32.

97 Giesen P, Smits M, Huibers L, et al. Quality of after-hours primary care in the Netherlands: a narrative review. Ann Intern Med 2011:155:108-13.

98 Harris T, McDonald K. Is the case-mix of patients who self-present to ED similar to general practice and other acute-care facilities? Emerg Med J 2014;31:970-4.

99 Heutmekers M, Naaldenberg J, Verheggen SA, et al. Does risk and urgency of requested out-of-hours general practitioners care differ for people with intellectual disabilities in residential settings compared with the general population in the Netherlands? A crosssectional routine data-based study. BMJ Open 2017;7:e019222.
100 Payne F. Utilization of out-of-hours services by patients with mental health problems. J Public Health 2000;22:302-6.

101 Philips H, Remmen R, De Paepe P, et al. Out of hours care: a profile analysis of patients attending the emergency department and the general practitioner on call. BMC Fam Pract 2010;11:88.

102 Keizer E, Bakker P, Giesen P, et al. Migrants' motives and expectations for contacting out-of-hours primary care: a survey study. BMC Fam Pract 2017;18:92.

103 Eichler K, Imhof D, Chmiel C, et al. The provision of out-of-hours care and associated costs in an urban area of Switzerland: a cost description study. BMC Fam Pract 2010;11:99.

104 Huber CA, Rosemann T, Zoller M, et al. Out-Of-Hours demand in primary care: frequency, mode of contact and reasons for encounter in Switzerland. J Eval Clin Pract 2011;17:174-9.

105 Gnani S, Morton S, Ramzan F, et al. Healthcare use among preschool children attending GP-led urgent care centres: a descriptive, observational study. BMJ Open 2016;6:e010672.

106 Lous J, Moth G, Huibers L, et al. Preschool children in Danish outof-hours primary care: a one-year descriptive study of face-to-face consultations. BMC Fam Pract 2019;20:36.

107 Hansen EH, Hunskaar S. Development, implementation, and pilot study of a sentinel network ("The Watchtowers") for monitoring emergency primary health care activity in Norway. BMC Health Serv Res 2008;8:62. 